\title{
Stage III Penile Cancer AJCC v6
}

National Cancer Institute

\section{Source}

National Cancer Institute. Stage III Penile Cancer A/CC v6. NCI Thesaurus. Code C7869.

Stage III includes: (T1, N2, M0); (T2, N2, M0); (T3, N0, M0); (T3, N1, M0); (T3, N2, M0).

T1: T umor invades subepithelial connective tissue. T2: T umor invades corpus

spongiosum or cavernosum. T3: Tumor invades urethra or prostate. N0: No regional

lymph node metastasis. N1: Metastasis in single superficial, inguinal lymph node. N2:

Metastasis in multiple or bilateral superficial inguinal lymph nodes. M0: No distant

metastasis. (AJCC 6th ed.) - 2003 